\title{
A Família nos Agroecossistemas Amazônicos: o caso do Complexo Ambiental Sacaí, Baixo rio Branco, Roraima, Brasil ${ }^{1}$
}

\author{
Thiago José Costa Alves², Sandra do Nascimento Noda ${ }^{3}$ e \\ Hiroshi Noda ${ }^{4}$
}

Resumo: Este estudo teve por objetivo caracterizar a família no movimento de conservação da autopoiese da vida nos agroecossistemas do Complexo Ambiental Sacaí, Caracaraí, Roraima, Brasil. A estrutura teórico-metodológica teve como base o paradigma da complexidade sistêmica a partir da categoria de análise organização autopoiética familiar estruturada como meio para compreensão do real, a partir do desenho da pesquisa como estudo de múltiplos casos. Foram aplicadas técnicas como entrevistas com roteiro prévio, questionário censitário, diários de campo e fotografias. Participaram deste estudo 41 famílias. O artigo revelou a necessidade, desde a conservação dos autos dos sujeitos, o entendimento das estruturas organizacionais primárias nos sistemas ecológicos humanos, os quais não são padronizáveis nem replicáveis em sua totalidade. Os resultados apontam para o Complexo Ambiental Sacaí como fruto do processo recursivo da autopoiese, em que, ao mesmo tempo, assume organização de família nuclear, de família extensa troncal e de família extensa comunitária. Dessa forma, o Complexo Ambiental Sacaí, enquanto uma organização agroecossistêmica, assume como ponto de partida para a conservação da autopoiese, a múltipla possibilidade de (re)construção da vida desde a organização familiar.

Palavras-chaves: autopoiese, organização agroecossistêmica familiar, família nuclear, família extensa troncal, família extensa comunitária.

\footnotetext{
Abstract: The objective of this study was to characterize the family's autopoiesis conservation movement in the agroecosystems of the Sacai Environmental Complex, Baixo rio Branco, Caracarai, Roraima, Brazil. The theoretical-methodological framework was based on the real understanding of the paradigm of systemic complexity. For this, it used a family of autopoietic organization analysis from the design of a multiple case study. Interviews with a previous script, census questionnaire,

1. Data de submissão: 13 de dezembro de 2016. Data de aceite: 20 de agosto de 2017.

2. Universidade Estadual de Roraima, Boa Vista, Roraima, Brasil. E-mail: thiago.uerr@gmail.com

3. Universidade Federal do Amazonas (in memorian). Manaus, Amazonas, Brasil. E-mail: snoda@ufam.edu.br

4. Instituto Nacional de Pesquisas da Amazônia. Manaus, Amazonas, Brasil. E-mail: hnoda@inpa.gov.br
} 
field diaries and photographs were used as evidence collection techniques. Forty-one families participated in this study. The paper revealed the importance of understanding the primary organizational structures in human ecological systems when considering conservation, which are not possible for standardization and replication in their entirety. From the results presented, it can be stated that the Sacai Environmental Complex, as a result of the recursive process of autopoiesis, at the same time, assumes organization as a nuclear family, troncal extensive family and community extensive family. Thus, the Sacai Environmental Complex, as an agroecossistemic organization, assumes the multiple possibility of life (re)construction from the family organization as a starting point for the conservation of autopoiesis.

Key-words: autopoiesis, family agroecossistemic organization, nuclear family, troncal extensive family, community extensive family.

Classificação JEL: P32, Q00, N56.

DOI: http://dx.doi.org/10.1590/1234-56781806-94790560309

\section{Introdução}

A Amazônia está presente em nove países da América Latina. No Brasil, compreende os estados do Acre, Amapá, Amazonas, Mato Grosso, Rondônia, Roraima, Tocantins, Pará e o Maranhão, na sua porção a oeste do meridiano $44^{\circ}$ (BRASIL, 2007). A floresta amazônica, principal bioma da Amazônia, apresenta-se como um sistema com organização e interações próprias repleto de paisagens singulares, recortadas por grandes rios e habitado por populações humanas diversas.

Essas populações humanas são responsáveis por construir, a partir do recurso ambiental disponível, lugares com estruturas societárias, às vezes com características de comunidades. Em Roraima, as populações ribeirinhas estão distribuídas predominantemente na porção sul do estado. Essas populações têm modos de vida estreitamente relacionados ao recurso ambiental disponível, os quais são revelados a partir de saberes singulares atrelados às trajetórias históricas desde o vivificado (MARIOTTI, 2001, p. 10). Apesar da diversidade e das distinções existentes nos modos de vida das populações amazônicas, é comum elas serem tratadas pelo Estado de forma semelhante, sem considerar tais particularidades, de forma linear, negligenciando e/ou invisibilizando os processos de (re)produção (BAREL, 1974; LEFEBVRE, 1983; DARNHOFER et al., 2016) e conservação da vida, identificados primariamente na forma como elas organizam-se desde a concepção da família.
Este estudo tem por objetivo caracterizar a família no movimento de conservação da autopoiese da vida (MATURANA et al., 2011) nos agroecossistemas do Complexo Ambiental Sacaí, Caracaraí, Roraima, Brasil. A importância da caracterização da primeira organização humana nos agroecossistemas amazônicos, a família, faz com que as escolhas de (re)produção social sejam reveladas em um contexto antes padronizados como estruturas ribeirinhas. Nesse sentido, a complexidade e a diversidade da família dão a cada agroecossistema estruturas distintas de escolhas no que tange à (re)construção da vida (ANDERSON et al., 2015; WALSH, 2016).

A localidade Sacaí, no Baixo rio Branco, foi a parte escolhida para compreensão do real, como um recorte de pesquisa, desde o forjamento do sistema real. Para tal, utilizou-se o conceito "complexo" atribuído por (GLIESSMANN, 2005, p. 78), substantivado a partir do termo Complexo Ambiental Sacaí, o qual denota a mesma estrutura complexa do sistema real; porém, em escala possível de consolidação investigativa em tempo hábil.

\section{Materiais e método}

O Complexo Ambiental Sacaí localiza-se no Baixo rio Branco, na parte sul do município de Caracaraí (Latitude +0:44:76; Longitude: -61:51:85), na margem direita do Rio Branco. Compreende 52 unidades habitacionais familiares, caracterizadas como unidades 
Figura 1. Mapa adaptado de IBGE (1983), com destaque para o complexo ambiental Sacaí Caracaraí, Roraima, Brasil

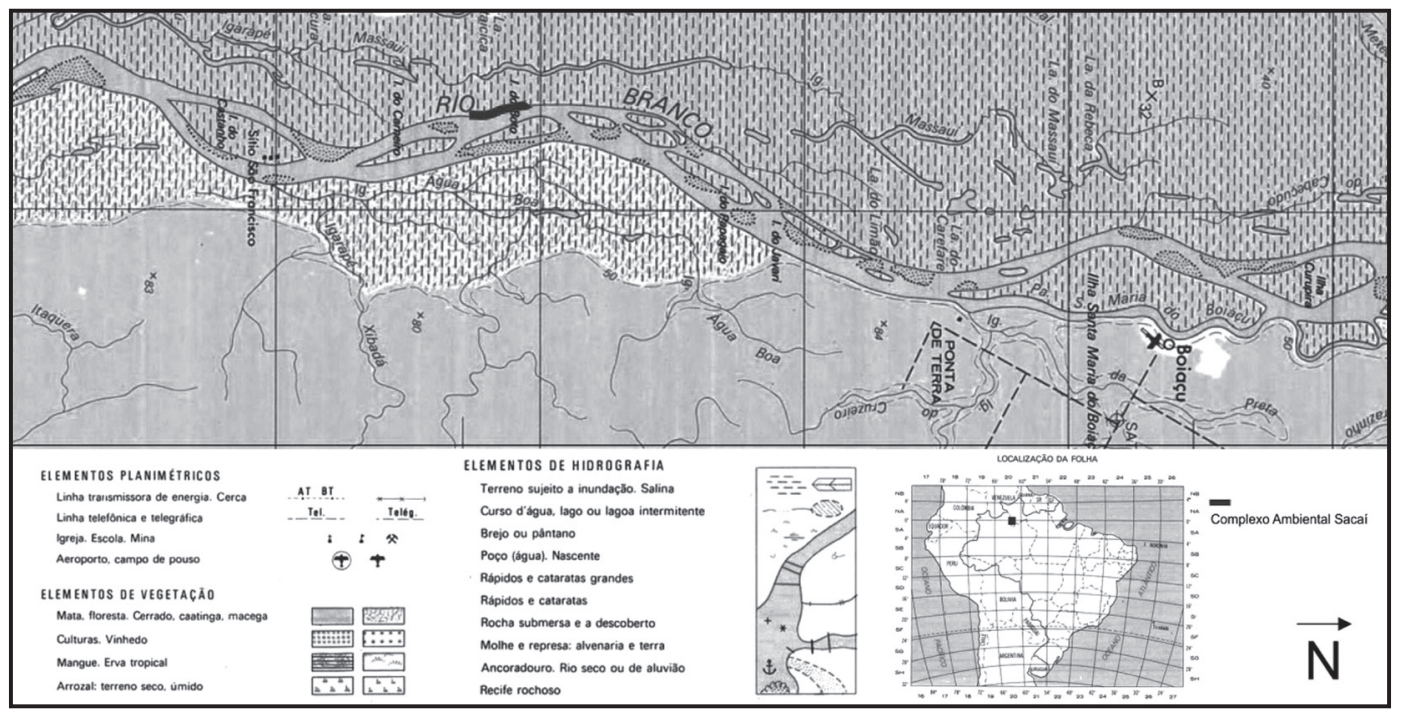

Fonte: Adaptado de IBGE (1983).

agrícolas familiares, as quais compõem a principal unidade de análise desse estudo. Para Noda (2000, p. 50) a agricultura familiar é caracterizada pela apropriação e pelo acesso aos bens, em que principalmente a terra e o trabalho estão intimamente ligados à família.

O rio Branco é o principal afluente da bacia do rio Amazonas no estado de Roraima. A bacia do rio Branco é composta pelos rios Tacutu, Uraricoera, Mucajaí e Anauá, e pelos seus respectivos afluentes (FEMACT, 2007a; FEMACT, 2007b). A bacia do rio Branco nasce da confluência entre as bacias dos rios Tacutu e Uraricoera (FEMACT, 2007a, p. 19).

O design utilizado para a pesquisa foi o estudo de múltiplos casos (YIN, 2010, p. 70) em que a unidade de análise foi constituída pelos agroecossistemas familiares do Complexo Ambiental Sacaí, Baixo rio Branco, Caracaraí, Roraima. Este estudo apresentou a sua lógica amostral analítica baseada na replicabilidade (YIN, 2010, p. 78) com coletas realizadas entre 2015 e 2016.

Os sujeitos da pesquisa foram selecionados de forma aleatória. As ferramentas e técnicas foram conduzidas primeiramente a partir de uma entrevista com roteiro prévio aplicadas em nove famílias nucleares. Para sua aplicação foram utilizados um gravador de alta captação, caderno de campo e roteiro de entrevista. Todas as entrevistas foram transcritas com auxílio do Express Scribe Transcription Software ${ }^{\circledR}$, corrigidas e organizadas a partir de nós temáticos no software MaxQDA ${ }^{\oplus}$.

A segunda fase de coleta de dados foi a aplicação do questionário censitário. Essa ferramenta foi aplicada para 41 famílias, com o objetivo de validar os dísticos obtidos na primeira fase, assim como aprofundar algumas evidências que não estavam totalmente claras. Foram consideradas nessa ferramenta aspectos do capital material para o trabalho e informações sobre propriedade. Os dados foram analisados e tratados por meio do Libre Office Calc ${ }^{\circledast}$, que, por sua vez, foram responsáveis pela produção de tabelas temáticas com médias e cruzamentos de dados. Durante todo o campo, duas ferramentas apareceram oportunamente como meios de suprir qualquer necessidade e vulnerabilidade das demais ferramentas: a) Diário de campo e b) Fotografia.

\section{Organização autopoiética familiar no Complexo Ambiental Sacaí}

A unidade de análise família é a primeira célula representante de organização existente no Complexo Ambiental Sacaí. Nesse sentido, este estudo se propõe a caracterizar a organização familiar desde a categoria 
de análise, a qual se constitui a partir da tríade conceitual: organização (MORIN, 2002; MORIN, 2008); autopoiese (MATURANA et al., 2011) e família (DA SILVA e LUNARDI, 2006). A categoria organização autopoiética familiar é estruturada no paradigma da complexidade sistêmica (MORIN, 2002, p. 136) desde a ordem trinitária conceitual formada pelo sistema, interações e organização, a qual é (retro)alimentada recursivamente por novos componentes emergenciais e impositivos, denominados por "todo-partes".

[...] as relações todo-partes devem ser necessariamente mediadas pelo termo interações; [...] a organização é o conceito que dá coerência construtiva, regra, regulação, estrutura às interações (MORIN, 2002, p. 136).

Para Walsh (2016, p. 10), a família caracteriza-se pelo alto grau de diversidade e modos de organização diretamente relacionado aos processos perceptivos de constituição da vida.

Para Morin (2002, p. 60), a organização compreende a estrutura física desnuda no sistema, em ordem e desordem. Seria a parte concreta de possível caracterização e acesso ao teórico e ao abstrato. A autopoiesis é componente da organização, descrito em Maturana e Varela (2011, p. 55). Em si, a autopoiése consiste no processo de autogeração no(s) sistema(s) e nas organizações. Para Maturana e Varela (2011, p. 55), o sistema autopoiético apresenta como característica peculiar a responsabilidade por levantar seus próprios cordões, e se constitui diferente por meio de sua própria dinâmica. As relações de existência confrontam em sua gênese a impossibilidade do padrão comportamental.

Para Da Silva e Lunardi (2006, p. 70), a unidade complexa "família" apresenta autonomia para se reproduzir e se auto-organizar, ao mesmo tempo em que é também dependente do ambiente em uma mistura de liberdade e autonomia, e para tal acessa dialogicamente a ordem e a desordem. Então a família (re)estrutura-se em ordem e desordem, preserva-se de forma recursiva e se (re)constrói de forma hologramática. Para Da Silva e Lunardi (2006), a definição do princípio hologramático se aproxima do processo de transmissão geracional, necessário na reprodução social familiar:

[...] o princípio hologramático, no qual as partes conservam o todo e este todo passa a ser mais que a soma das partes, pode ser visuali- zado na família se considerarmos, por exemplo, que cada um de seus membros carrega consigo os valores, os símbolos, as crenças, as normas, os vínculos, as noções de limite, de respeito, os quais são mantidos na família e são repassados através das gerações (p. 71).

As estruturas apresentadas como organização autopoiética familiar no Complexo Ambiental Sacaí não são, portanto, passíveis de padronização teórica e comportam em si, como movimento recursivo, suas próprias interações no sistema.

As tipologias de família existentes no Complexo Ambiental Sacaí seguem a lógica organizacional de uso do recurso ambiental a partir do trabalho. Nesse sentido, é proposto aqui o uso da variável capital material $^{5}$ como primeira aproximação na compreensão do desenho familiar. O Complexo Ambiental Sacaí é formado por agricultores que desempenham o trabalho de agricultura no ambiente a partir da unidade familiar, caracterizando-se como agricultores familiares.

Para Noda et al. (2006, p. 163), a agricultura familiar é considerada a modalidade de agricultura em que a unidade de produção tem como base principal o trabalho da família (BRASIL, 2006) na Lei no 11.326, de 24 de julho de 2006, responsável por estabelecer a Política Nacional de Agricultura Familiar, considera agricultor familiar aqueles que atendem simultaneamente aos seguintes requisitos:

I - não detenha, a qualquer título, área maior do que 4 (quatro) módulos fiscais; II - utilize predominantemente mão de obra da própria família nas atividades econômicas do seu estabelecimento ou empreendimento; III - tenha percentual mínimo da renda familiar originada de atividades econômicas do seu estabelecimento ou empreendimento, na forma definida pelo Poder Executivo; IV - dirija seu estabelecimento ou empreendimento com sua família.

5. Segundo Gorz (2005, p. 19), o termo capital material remete à estrutura produtiva física existente, desde ferramentas, espaços físicos no processo de produção, mesmo que indispensável em relação à criação do valor, representado pelo autor pelo valor cognitivo e de conhecimento a partir do capital imaterial. Para Gorz (2005, p. 38), na era do valor do conhecimento, o capital material cumpre a função subalterna, relegada à vassalagem do sistema produtivo, pois não acomoda em si o valor do trabalho cognitivo ao capital do conhecimento. 
Noda (2007, p. 18) pontua a reprodução biológica e social da unidade agrícola como característica existencial da agricultura familiar. A família portanto, nessa definição, assume papel central no gerenciamento e condução das atividades.

No Complexo Ambiental Sacaí, é possível identificar três formatos interdependentes de família, são elas: a) a família nuclear; b) a família extensa troncal e c) a família extensa comunitária (Figura 2). Esses formatos apresentam distinções e multiplicidade de estratégias de reprodução social, associadas à possível plasticidade comportamental exigida diante dos estresses de ordenamento e desordenamento contidos no ambiente.

As tipologias de organização familiar identificadas interagem entre si, nos níveis de necessidades existentes, da seguinte forma: a) às relacionadas às necessidades da família nuclear; $b$ ) àquelas que não podem ser supridas pelas famílias nucleares e necessitam do capital material da família extensa troncal e c) àquelas que não podem ser supridas pela família extensa troncal que, por sua vez, necessitam do capital material da família extensa comunitária.

A organização autopoiética familiar no Complexo Ambiental Sacaí apresenta a plasticidade necessária para prover a reprodução social das famílias. Como rota de construção dessa parte do estudo é possível identificar quais pontos nos levam a acreditar nesta plasticidade do unitas multiplex familiar, estruturado explicativamente desde os três tipos organizacionais identificados.

\section{A família nuclear}

A família nuclear é a primeira organização possível de ser acessada no Complexo Ambiental Sacaí. O conceito apresentado por Faco e Melchiori (2009, p. 121) sobre família nuclear sugere estarem contidos nessa estrutura os pais, os filhos e as pessoas ligadas por afinidade e por rede de relações. No caso do Complexo Ambiental Sacaí, as estratégias contidas na organização dessa estrutura familiar para o trabalho no ambiente possibilitam o acesso a quatro elementos caracterizadores desse tipo de organização, são eles: a) a casa; b) a posse da propriedade, c) os filhos e d) a capitalização material.

A casa, à primeira vista, pode simbolizar o lugar da família, que funciona como centro nevrálgico e dissipador da família nuclear, assim como das outras estruturas familiares existentes no Complexo Ambiental Sacaí. De acordo com a Figura 3, 90,24\% (n = 37) das famílias têm casa própria; $87,80 \%(\mathrm{n}=36)$ têm somente uma casa, 9,76\% ( $n=4)$ têm a casa cedida ou alugada, enquanto que, em $2,44 \%(n=1)$ dos casos, os sujeitos têm três casas.

A propriedade, por sua vez, é a extensão da casa, lugar seguro onde pode ser desempenhado o trabalho. A posse dessa propriedade, contudo, não parece estar bem definida. Segundo os dados coletados, $41,46 \%$ $(\mathrm{n}=17)$ dos sujeitos entrevistados afirmaram ter a documentação de propriedade da terra, enquanto que $53,66 \%(n=22)$ disseram não apresentar qualquer tipo de documentação.

Figura 2. Representação etic da organização autopoiética familiar no complexo ambiental Sacaí-RR (2016)

Família nuclear

(fn1, fn2, fn3, fnn..., fn41)
Família extensa troncal

(fet1, fet2..., fetn, fet5)
Família extensa comunitária

(fec1)

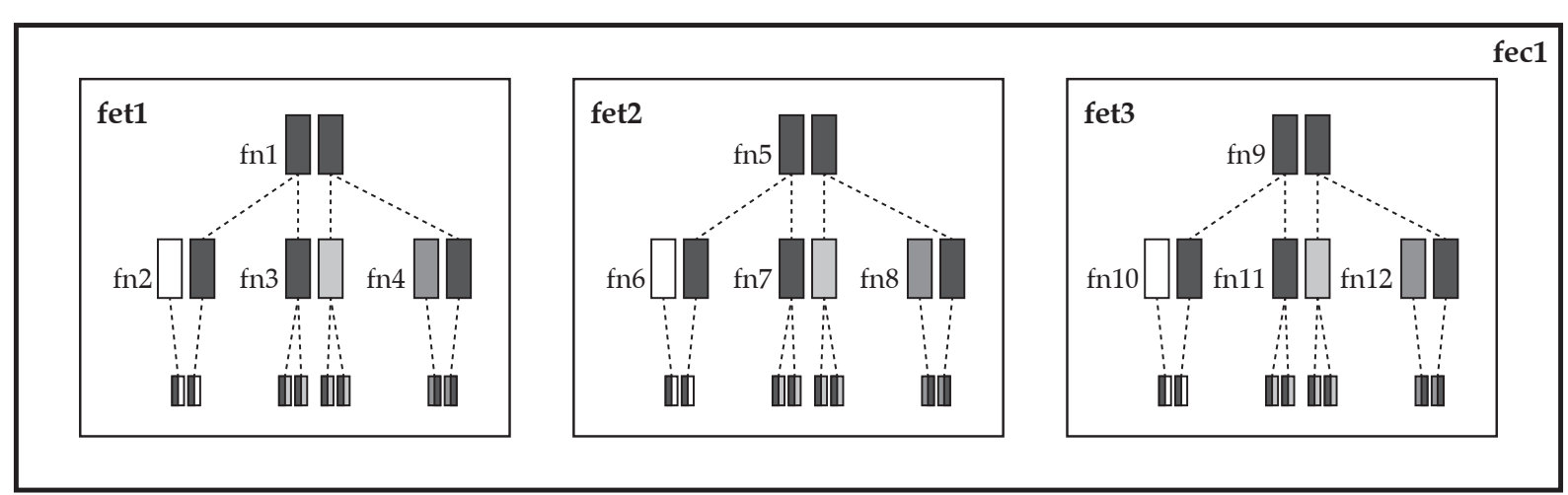

Fonte: Elaborada pelos autores. 
Figura 3. Representação de caracterização etic da família nuclear no complexo ambiental Sacaí-RR (2016)

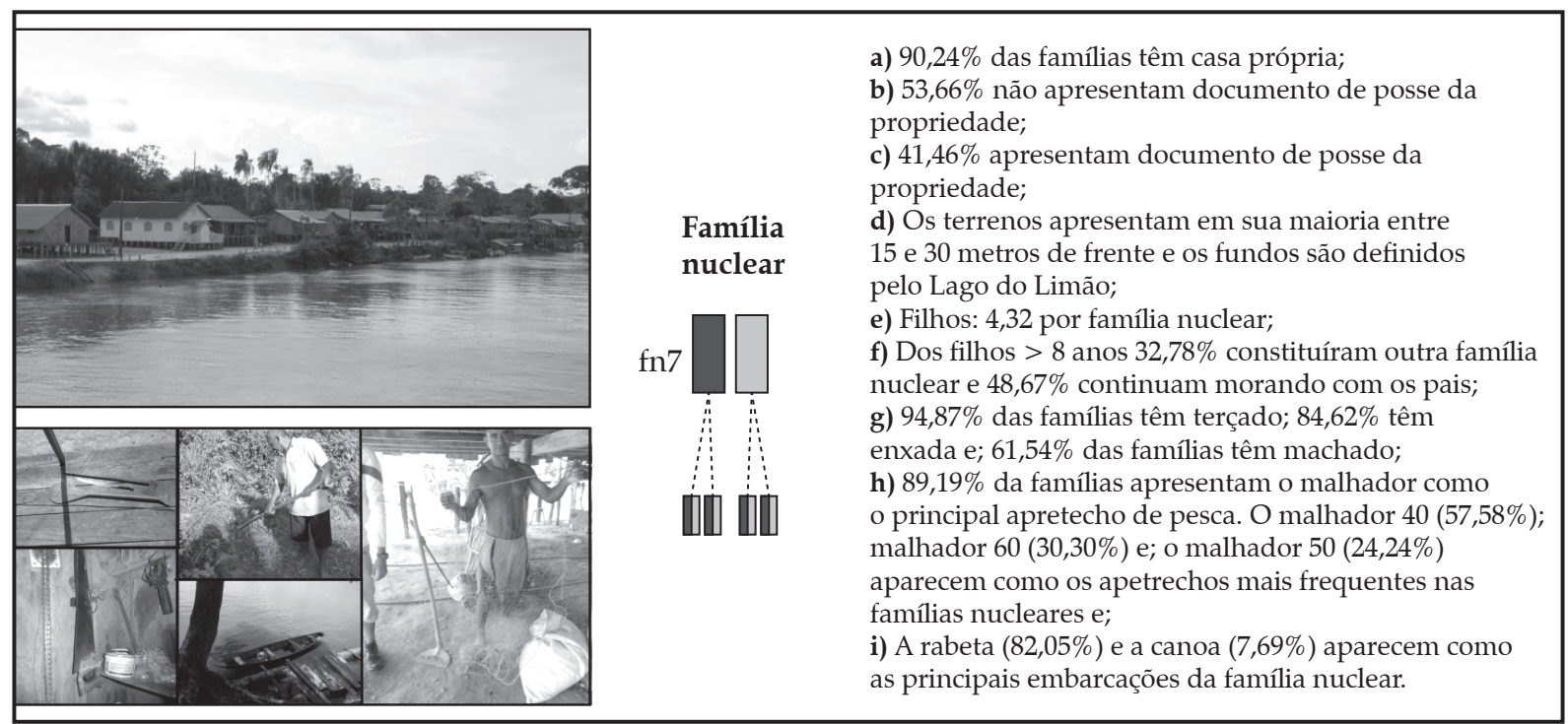

Fonte: Elaborada pelos autores.

Dentre os tipos de documentos mencionados, o mais frequente foi o documento emitido pelo Iteraima (Instituto de Terras e Colonos de Roraima). O Art. $5^{\underline{0}}$ do Decreto no 9699, 2009, que trata da criação e função do Iteraima, descreve a finalidade deste órgão da seguinte forma:

Art. 5o O Iteraima tem por finalidade elaborar e executar a política fundiária do Estado investido de poderes para promover a discriminação, arrecadação das terras públicas e devolutas ou aquelas transferidas da União, por força da Lei ou incorporadas por qualquer meio legal ao Patrimônio Estadual, bem como a normalização de áreas urbanas, rurais e bens imóveis de domínio e posse do Estado (Roraima, 2009, p. 1).

Ao mencionar os documentos de posse, a maioria dos agricultores familiares não explicitam qual o tipo de documento emitido pelo Iteraima. Alguns sujeitos mencionam ter o "título definitivo", fato caracterizador do evidente o desconhecimento sobre a real situação da propriedade das terras ocupadas. Segundo Arantes (2009 p. 133), até 2006, o Complexo Ambiental Sacaí apresentava 91 lotes, 49 em área de várzea (incluídas áreas da sede) e 42 em área de terra firme (lotes rurais correspondente às áreas de roça e sítios em terra firme) ${ }^{6}$, dos quais tinham autorização de ocupação e situação de posse a regularizar. A situação de dúvidas foi agravada desde os escândalos de corrupção envolvendo o órgão estadual supracitado, em que boa parte dos títulos emitidos entre 2010 e 2013 foram considerados suspeitos pelo Ministério Público Federal, que sugeriu a sua anulação (Lima, 2013).

“[...] não, tem não, tem nada não. [...] está aqui, eu tenho aqui da minha terra, é da prefeitura, só que dizem que não vale, diz que não está valendo" (A.B.S., 65 anos, Complexo Ambiental Sacaí).

“[...] tem um documento mas eu não estou a par disso mais, mais do que isso não deve ter não" (E.C.A., 58 anos, Complexo Ambiental Sacaí)!

6. As roças no Complexo Ambiental Sacaí estão alocadas historicamente nas Várzeas (Va) e nas Terra firmes (Tf). Nesse sentido, a composição paisagística das roças apresentam-se de forma distinta, pois contam com o pulso das águas como sua principal variável. As roças são organizadas na maioria pelas famílias nucleares, em quadras e na maioria dos casos está relacionada ao plantio de mandioca e macaxeira (manihot esculenta Crantz) para a produção de farinha. 
Mesmo diante do exposto, a situação fundiária não parece ser um entrave para a reprodução social das famílias que lá vivem. Uma prova disso é o surgimento de um sistema próprio de negociação e distribuição das propriedades o qual ignora processos burocráticos de registro e regularização.

“[...] rapaz, aqui está tudo embolado [...] essa daqui é minha, essa daqui é da minha mãe, essa daqui é da minha irmã, aquela ali é da vizinha. [...] dali para cá daria uns trinta metros" (F.S.S., 27 anos, Complexo Ambiental Sacaí).

“[...] é assim, chega aí pede um pedaço e se a pessoa tiver um bom coração né, libera porque tem muitos que liberam não, tem muitos que querem um canto espaçoso. [...] eu não, eu tendo minha casinha aí, tendo terreno pra dar até lá em baixo, lá. Aliás, na minha roça, [...] um rapaz que pediu pra fazer uma casa lá no meio [...] aí eu cedi pra ele" (J.M.N.S., 30 anos, Complexo Ambiental Sacaí).

“[...] não, daqui por exemplo ninguém nunca, porque o pessoal do Iteraima veio tirando, do Iteraima mesmo. Só que eu não estava aqui, esse terreno aqui é da minha outra irmã, eu comprei dela, eu morava com a mamãe, e depois que eu me juntei eu comprei dela a casa e o terreno. Essa casa está tudo no documento da mamãe, no documento" (F.S.S., 27 anos, Complexo Ambiental Sacaí).

Ainda no que se refere à propriedade, a extensão dos terrenos onde estão inseridas as casas na várzea, apresentam tamanhos diferenciados. De maneira geral, o discurso indica que a maioria das propriedades possui 30 metros de comprimento de frente do terreno e os fundos sem metragem definida. Nesse sentido, em linha reta, desde a casa até um ponto simbólico paisagístico, o terreno pertence ao dono daquela casa.

“[...] 30 metros de frente, e de fundo não tem. [...] até a beira do Limão. [...] a gente explora aqui só até onde o senhor tá vendo. Até mais ou menos ali, uns cem metros de fundo mais ou menos se der. [...] continuei até um pedaço para fazer um campo de futebol, mas alaga pois é muito baixo" (J.C.A., 50 anos, Complexo Ambiental Sacaí).
“[...] é de 30. Para cá eu não sei [referindo aos fundos da propriedade], agora aqui é trinta de frente" (D.A.S., 76 anos, Complexo Ambiental Sacaí).

“[...] rapaz, quando tiravam aqui era 25 metros. É, agora o comprimento nunca foi medido, não" (R.B.C., 58 anos, Complexo Ambiental Sacaí).

“[...] Se tiver ela tem 30 metros de frente mais ou menos" (E.C.A., 58 anos, Complexo Ambiental Sacaí).

É possível notar o estabelecimento de uma organização fundiária própria no Complexo Ambiental Sacaí, a qual surge da inoperância do Estado. No tocante ao terceiro elemento caracterizador da família nuclear, "os filhos", os dados revelam uma estrutura familiar predominantemente formada pelo casal e pelos filhos. Somente em um dos casos estudados a família não tem filhos. Também é possível identificar um pequeno número de componentes agregados de ( $n=3)$, os quais seriam formados também por maridos e esposas dos filhos(as) que não saíram da casa dos pais (Figura 3). Conforme exposto na Figura 3, contabilizou-se a existência de 177 filhos, com média de 4,32 filhos por unidade familiar $(n=41)$. Para compreender o papel desempenhado pelos filhos na unidade familiar, por meio do trabalho, optou-se por categorizar os dados em "filhos maiores de oito anos em casa" e "fora de casa" e "filhos menores de oito anos em casa" e "fora de casa" (Figura 3). De acordo com Leme e Begossi (2004), as crianças até os oito anos entram em um processo de aprendizado lúdico, em que aprendem o trabalho brincando e somente após essa faixa etária começam a ajudar no trabalho familiar.

No Complexo Ambiental Sacaí, dos 64 filhos menores de oito anos, 60 moram na casa dos pais e quatro moram em outras localidades. Os filhos moradores fora de casa dificilmente retornarão para trabalhar na propriedade familiar. Aos filhos permanecentes no núcleo familiar será destinada a responsabilidade de assegurar a continuidade do trabalho nas próximas gerações.

Dos 113 filhos maiores de oito anos, 55 ainda vivem em casa com os pais. Nesse contexto, estes filhos representam hoje a geração com trabalho efetivo nas propriedades nucleares. Como elemento de reprodução social e continuidade da instituição família está, 
portanto, presente a (re)construção do saber ambiental. Essa transmissão de saberes (DELBOS et al., 1984, p. 105) é evidente nos dísticos de alguns dos sujeitos entrevistados.

"[...] eu continuo as atividades do papai. Aí a gente roça, aí derruba né! Primeiro a gente roça, aí tem gente que deixa secar aquele mato mais fino debaixo, aí derruba o de cima que é mais grosso, aí deixa secar, quando seca toca fogo, aí tem o processo de coivarar, pessoal chama né! [...] coivarar é tirar os pau do meio. [...] deixar a terra limpa, tem muita gente que não faz isso não, aí planta" (J.M.N.S., 30 anos, Complexo Ambiental Sacaí).

“[...] na seringa, né? Lá eu era menino e comecei a andar na estrada no mato, ajudava meu pai, tinha 12 anos, por aí eu fui levando e aí fui crescendo, crescendo e me casei lá, aí cortei seringa uns tempos" (A.J.Q., 65 anos, Complexo Ambiental Sacaí).

Nesse sentido, o filho segue uma lógica de aprendizado e transmissão do saber existente no trabalho, aquele considerado como trabalho imaterial no ambiente. Gorz (2005) ao tratar de como se dá a construção do trabalho imaterial desde aquilo que é feito e vivificado, explicita da seguinte forma:

[...] para saber falar, é preciso abandonar completamente a relação cognitiva com a língua falada. O saber é feito de experiências e práticas, tomadas evidências intuitivas, hábitos; e a inteligência cobre todo o leque das capacidades que vão do julgamento e do discernimento à abertura do espírito, à aptidão de assimilar novos conhecimentos e de combiná-los com os saberes (p. 17).

A importância da transmissão geracional de saberes de pai para filho, assim como de filho para neto, a partir do trabalho imaterial, está diretamente relacionado ao processo de continuidade da reprodução social nos agroecossistemas familiares. Nessa lógica, a família nuclear assume um papel central na conservação desse sistema.

Seguindo a lógica natural de amadurecimento e crescimento familiar, os filhos, ao atingirem a juventude, casam e passam a ser responsáveis por novas unidades familiares, constituindo, portanto, novas famílias nucleares. Dos 113 filhos maiores de oito anos, $32,78 \%$ ( $n=58$ ) já saíram de casa para formar outras famílias no Complexo Ambiental Sacaí ou migraram para outras localidades. No primeiro caso, por permanecerem perto da unidade familiar dos pais, os filhos acabam assumindo um importante papel no suporte ao trabalho na unidade familiar no caso de envelhecimento dos pais. Esse papel se justifica em virtude do envelhecer no Complexo Ambiental Sacaí se traduzir em limitação física e na impossibilidade de executar o trabalho da mesma forma como executavam quando eram jovens. No dístico de um dos sujeitos é possível notar a importância do trabalho dos filhos para os pais, quando mais velhos.

“[...] com todos eles posso contar, todos eles. [...] quando chegamos aqui, graças a Deus, meus filhos todos têm diferença para agora. [...] eu sabia que se eu não fosse é pescar, se eu não fosse plantar, depois eu não tinha o que eu quero [...]" (A.B.S., 65 anos, Complexo Ambiental Sacaí).

Assim como a importância atribuída à casa, à propriedade e aos filhos na caracterização da organização autopoiética familiar, o capital material é também bastante esclarecedor sobre o formato organizacional ali existente. A capitalização material da família nuclear no Complexo Ambiental Sacaí é expressa a partir das roças, do barco "rabeta" e dos apetrechos de caça e pesca.

Ferramentas como terçado, machado e enxada são predominantes dentre o capital material relacionado a roça por unidade familiar nuclear (Figura 3). Dentre as embarcações pode-se citar a rabeta $(82,05 \%)$ e a canoa $(7,69 \%)$ como meio de transporte característico da unidade familiar (Figura 3). A rabeta nada mais é do que uma adaptação da canoa com o motor, e, devido ao seu tamanho e consumo reduzidos, apresenta alta frequência nas unidades familiares. Para Leme e Begossi (2004, p. 109), ao tratar da frequência de uso de embarcações utilizadas para pesca por agricultores familiares do rio Negro, barcos motorizados aparecem como $30 \%$ de uso, enquanto que canoas a remo ocupam outros $70 \%$ da frequência encontrada diferindo da realidade observada no Complexo Ambiental Sacaí.

Como capital material atrelado aos sistemas produtivos da família nuclear é possível identificar no extrativismo de produtos florestais não madeireiros 
a peconha $(84,62 \%)$ e, no extrativismo madeireiro, a motosserra $(38,46 \%)$ (Figura 3$)$. No tocante à atividade da pesca, a diversidade de apetrechos por unidade familiar é evidentemente mais elevada. $\mathrm{O}$ malhador apresenta-se como apetrecho mais frequente tendo sido identificados nove tamanhos de malhadores como capital material da família nuclear (Figura 3).

Essa diversidade refere-se à distância entre os nós aplicados na trama do malhador, a qual é adequada a diferentes tipos de pescado. Para Leme e Begossi (2004, p. 109), o emprego das tecnologias de pesca diferem de acordo com o objetivo de pesca, tipo e sazonalidade dos recursos explorados. Nesse sentido, o capital material aplicado na produção, aqui exemplificado pelo malhador, se conecta diretamente à especialidade do saber ambiental destinado à pesca. Outros 11 apetrechos aparecem como capital material empregado no sistema produtivo pesqueiro. Destes, oito, além do já mencionado malhador, relacionam-se diretamente à unidade familiar nuclear (Figura 3).

Muito embora a família nuclear apresente estrutura de trabalho bem definida, as relações de parentesco e o compartilhamento de apetrechos mostra que esta não é uma estrutura isolada. Nesse sentido, a partir das necessidades emergentes que não podem ser imediatamente supridas nos limites da família nuclear surge outra estrutura familiar aqui denominada "família extensa troncal".

\section{Família extensa troncal}

O conceito de família extensa troncal apresentado por González (1991, p. 179) consiste na existência de uma haste relacionando diferentes gerações de casais conjugais, em que todas as hastes criadas das estruturas conjugais são como uma única estrutura. $\mathrm{O}$ autor faz menção e ênfase à existência de uma haste ligando as diferentes gerações de casais a um suporte dorsal familiar (Figura 4).

Para Sánchez (2008, p. 18), a principal característica diferenciadora entre a família nuclear e a família extensa troncal é a existência de um lugar nuclear onde as pessoas, no papel dos tios, sobrinhos e netos podem contar em situações de necessidade. No Complexo Ambiental Sacaí, a família troncal é reconhecida a partir de uma haste relacionada a estruturas básicas de produção, sendo responsáveis por ligar várias gerações de filhos às famílias nucleares mais antigas.

De acordo com a Figura 4 é possível identificar vasto grupo de utensílios que apresentam o uso compartilhado pela família extensa troncal, são eles: a) no trabalho da roça: a motosserra; $b$ ) no extrativismo e beneficiamento madeireiro: a serra circular e a plainadeira; c) no extrativismo animal: a espingarda; d) no extrativismo do açaí: a máquina de bater açaí; e) na pesca: o espinhel, a poita e alguns tipos de malhadores e f) nos meios de transporte: o barco geleiro, o bote e o batelão.

Figura 4. Representação de caracterização etic da família extensa troncal no complexo ambiental Sacaí, RR (2016)

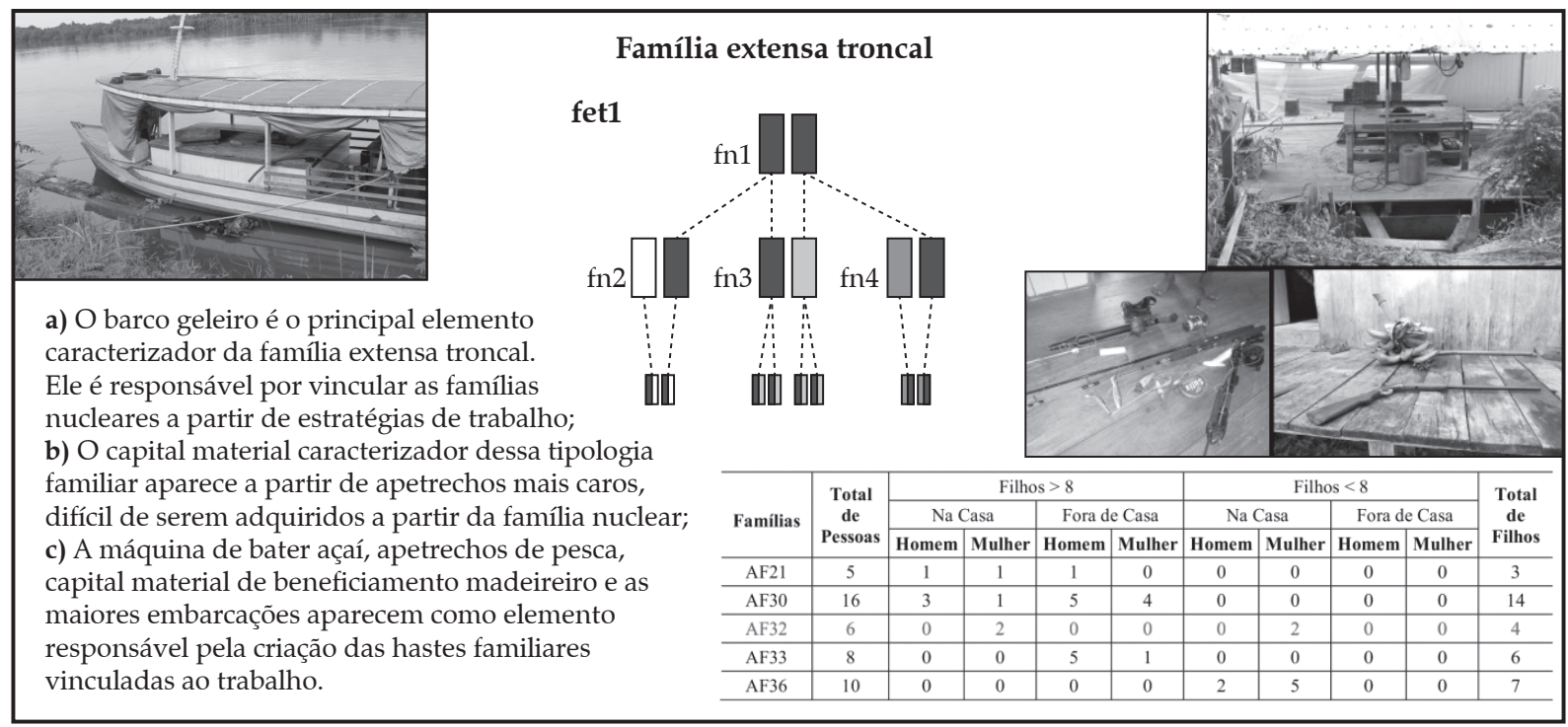

Fonte: Elaborada pelos autores. 
Este grupo de utensílios compartilhados pela família extensa troncal apresenta características de aquisição mais criteriosa, talvez pelo alto custo. Nesse sentido, o barco geleiro aparece como um componente material bastante representativo para a caracterização da família extensa troncal. Na Figura 4, no universo de 41 famílias nucleares, cinco são detentoras de barco geleiro, são elas: AF21, AF30, AF32, AF33 e AF36. Dessas, somente a AF32 não apresenta características de família extensa troncal, pois não possui relações familiares geracionais, nem relações de uso que ultrapassam as relações sanguíneas. Já as famílias AF21, AF30, AF33 e AF36, apresentam características de família extensa troncal, uma vez que fazem o uso compartilhado do barco geleiro.

Em um dos casos (AF30), é possível identificar uma família extensa troncal formada por 51 pessoas. Dessas, 14 são a primeira geração de filhos de um casal. Desse grupo de filhos, quatro mulheres e quatro homens estabeleceram-se no Complexo Ambiental Sacaí constituindo novas famílias nucleares. Três filhos migraram para estudar em outras localidades e três filhos maiores de oito anos ainda vivem na casa com os pais. Ainda compõem a família extensa troncal do AF30 34 netos e um bisneto.

O barco geleiro se apresenta como útil em pelo menos três situações distintas: como meio para deslocamento entre as localidades; como meio de navegação estável em rio com maior vazão, o caso do rio Negro e como meio de escoamento da produção a ser comercializada nas cidades de Caracaraí e Manaus. Em relação aos mecanismos de comercialização da produção do Complexo Ambiental Sacaí, o barco geleiro surge como estratégia de comercialização da pesca, do açaí e dos produtos da roça. Nos dísticos, os sujeitos afirmam se tratar de uma embarcação com maior capacidade de acomodação da produção, tanto em capacidade quanto em dias.

“[...] esse aí faz cinco toneladas [referente ao novo barco que está sendo construído]. Esse aí meu faz $2.125 \mathrm{~kg}$. Só que ele é muito pequeno" (J.C.A., 50 anos, Complexo Ambiental Sacaí).

"[...] é um geleiro, ele aguenta o gelo na base de 20 dias" (A.B.S., 65 anos, Complexo Ambiental Sacaí).

No tocante à navegabilidade, devido ao fato de o Complexo Ambiental Sacaí estar localizado entre as sedes das cidades de Caracaraí e Manaus, o acesso a essas localidades dá-se por dois rios com navegabilidade distintas. Embarcações como a rabeta e a canoa, presentes em todas as famílias nucleares, não navegam em rios maiores (p. ex. rio Negro), com maior vazão, devido à insegurança provocada pelo banzeiro. Com as limitações de acesso e com ausência de transporte modal, o deslocamento por motivações de cuidados de saúde, regularização de documentação e benefícios sociais também acabam por ser necessários no contexto de reprodução social. O barco geleiro figura nesse contexto, como o principal capital material da família extensa troncal para suprir as demandas acima mencionadas.

"[...] para ele viajar para Caracaraí ele ainda vai, mas para Manaus é muito perigoso" (J.C.A., 50 anos, Complexo Ambiental Sacaí).

“[...] às vezes nós vamos para Caracaraí com motor [barco geleiro]. Um dia aconteceu de alguém da minha família vim me pedir passagem, e nós pagamos passagem em outro barco para eles irem, para eles não pagarem. Porque muitos deles, coitados, não têm um pouco de condições adequadas, aí tirar o pouco que tem para pagar passagem iria fazer falta para os filhos deles" (J.C.A., 50 anos, Complexo Ambiental Sacaí).

Conforme observado, as relações de compartilhamento de parte do capital material criam a haste capaz de conectar diversas famílias nucleares em uma nova estrutura familiar troncal. No entanto, a reprodução social no Complexo Ambiental Sacaí não se sustenta por completo a partir da existência das famílias nucleares e troncais, fazendo emergir uma terceira tipologia familiar aqui denominada por "família extensa comunitária".

\section{Família extensa comunitária}

Em seu terceiro estádio de organização autopoiética familiar aparece a família extensa comunitária. Para Caniço et al. (2010, p. 27), a família comunitária caracteriza-se por um grupo de homens e mulheres e seus descendentes, coabitando ou morando em casas separadas habitualmente próximas e com regras 
comunais. Mesmo que não completamente enquadrados no conceito exposto por Caniço et al. (2010), os traços da família comunitária evidenciados no Complexo Ambiental Sacaí, a partir dos dados coletados, revelam relações não parentais a partir do surgimento do elemento "amigo".

O primeiro passo para caracterização dessa tipologia familiar deu-se a partir da sua autodenominação. A autodenominação família no Complexo Ambiental Sacaí apresenta-se como uma estrutura coletiva, em que o conjunto de todas as famílias nucleares e extensas troncais dão origem a uma única e grande família (Figura 5).

"[...] é isso, aqui é uma família só" (J. Q., 33 anos, Complexo Ambiental Sacaí).

“[...] uma família só, uma família grande. Nós todos aqui somos uma família só" (R.B.C., 58 anos, Complexo Ambiental Sacaí).

"[...] todo mundo aqui é família, porque qualquer um deles a gente pode contar. [...] mas tem uns que nós consideramos mais" (A.B.S., 65 anos, Complexo Ambiental Sacaí).
“[...] é, são amigos, pode, pode, pois é. [...] eu ajudo eles como uma família, o que eles comem a gente come, então se for comida lá manda para a gente também então é uma família né" (M.P.S., 55 anos, Complexo Ambiental Sacaí).

“[...] pois é, essa menina não tinha nem nascido, eu conheci eles aqui e aqui é minha família" (A.J.Q., 65 anos, Complexo Ambiental Sacaí).

Dois elementos caracterizadores da família extensa comunitária são identificados nos dísticos dos sujeitos, são eles: "as redes de reciprocidade" e o "trabalho coletivo". Esses elementos derivam de estratégias de reprodução social e, para Radomsky e Schneider (2007, p. 252), assumem papel fundamental para a manutenção dos laços societários capazes de envolver diferentes atores sociais ligados por características como parentesco, amizade, etnia, entre outros. Nessa mesma linha, outros autores (RADOMSKY et al., 2007, p. 252; PERONDI et al., 2012, p. 123; SABOURIN, 2015, p. 4) apresentam a reciprocidade como estratégia de consolidação das relações sociais projetadas em um lugar. Este lugar, constituído topofilicamente, é caracterizado

Figura 5. Representação de caracterização etic da família extensa comunitária no complexo ambiental Sacaí-RR (2016)

\section{Família extensa comunitária}

a) O status de comunidade está estreitamente relacionado ao modo como os sujeitos afirmam que toda a comunidade é uma única família; b) É possível identificar a existência de redes de reciprocidade as quais estão diretamente relacionadas a esta tipologia de organização autopoiética familiar;

c) As redes de reciprocidade puderam ser evidenciadas nas doações de áreas de roças para novos moradores; no compartilhar da caça com os vizinhos e; na ajuda mútua em momentos de impossibilidade de exercer o trabalho;

d) O trabalho coletivo, como característica comunal, aparece desde a existência de uma casa de farinha coletiva, de casa de farinhas privadas compartilhadas e nos multirões para aceleração da colheita da roça em períodos que a cheia ameaçã a produção e;

e) $82,9 \%$ dos sujeitos não possuem casa de farinha própria;

$51,2 \%$ dos sujeitos faz uso da casa de farinha comunitária e;

$31,7 \%$ faz uso da casa de farinha de outro agricultor.
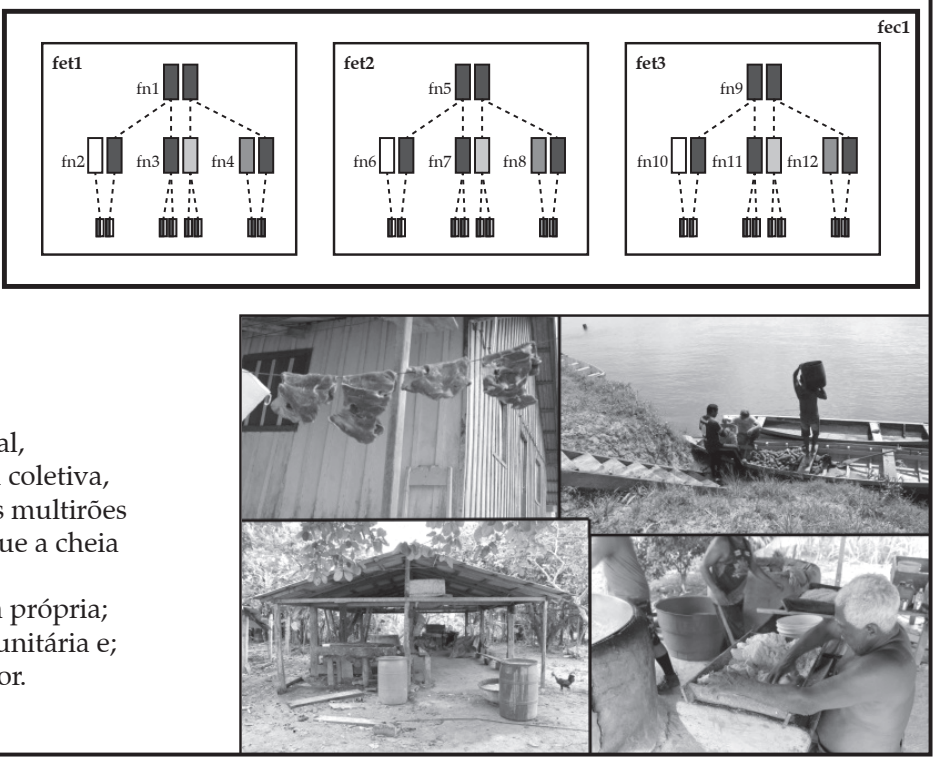

Fonte: Elaborada pelos autores. 
a partir do elo entre a paisagem e o sentimento (TUAN, 2012, p. 5).

Assim, as redes de reciprocidade ultrapassam as relações parentais consanguíneas e apresentam-se manifestas no Complexo Ambiental Sacaí a partir do trabalho, das seguintes formas: a) nas doações de áreas de roça para novos moradores; b) no compartilhamento da caça com os vizinhos e c) na ajuda mútua em momentos de impossibilidade de exercer o trabalho. A relação de reciprocidade é uma via de duas mãos. A mesma mão receptora é a mesma mão doadora. A relação de dependência e confiança construída a partir da reciprocidade desde a estratégia de compartilhamento pode ser notada nos próximos dísticos.

“[...] depois que a gente foi lá para terra firme por meio dos meus vizinhos que moravam aqui, aí que eles deram um terreno para gente, aí que foram começar a roça" (J.C.A., 50 anos, Complexo Ambiental Sacaí).

“[...] eu fui só dar uma ajuda aqui para eles. É amigo, se eu chegar aqui e tiverem comendo, eles me chamam e eu como. Se eu vier com fome eu como, se eu estiver com a barriga cheia não. - Tem comida aí? Aí ele diz: - tem aí na panela, vai lá! Aí é o mesmo que estar na minha casa. [...] é como se fosse parte da família, amizade que pegou desde quando eu cheguei aqui. [...] quando eu chego aqui, ali na casa de [nome suprimido], se tiver comida e eu estiver com fome e tiver lá eu como. Se chegar, vamos dizer [...] lá nos filhos dela: - ah! eu estou com fome. - Tem comida, tem feita ali na panela? se não tiver tem na feira se não quiser? - Tire aí que eu faço" (A.J.Q., 65 anos, Complexo Ambiental Sacaí).

“[...] então quando eu vou matar assim, até para ela mesmo eu dou [em relação a uma vizinha], eu dou paca. Quando eu mato assim dois ou três mutum, aí eu dou! Já tem dado um pra ela, não é toda vez, porque a gente tem uns amigos aqui, aí para cada um dá um pedaço pra um, um pedaço para o outro" (A.J.Q., 65 anos, Complexo Ambiental Sacaí).

“[...] Ajuda, as vezes para levar uma pessoa para ali para Santa Maria, quando as vezes o cara não tem gasolina. Aí sai um atrás de gasolina, assim por doença, atrás de gasolina aí a gente um dá um litro, outro dá dois, outro dá um, dá dois, aí de repente enrola naquele negócio e vamos embora" (A.J.Q., 65 anos, Complexo Ambiental Sacaí).

No tocante à capitalização material da família extensa comunitária no Complexo Ambiental Sacaí para o trabalho coletivo, a casa de farinha é bastante representativa, pois aparece como estrutura essencial para beneficiamento do principal produto da roça, a mandioca (manihot esculenta Crantz). Nesse sentido, é importante destacar que somente $17,95 \%(n=7)$ dos sujeitos entrevistados apresentam casa de farinha própria e 53,85\% ( $n=21$ ) fazem uso da casa de farinha comunitária (Figura 5). A casa de farinha comunitária é uma construção coletiva da compensação dada como contrapartida da prefeitura de Caracaraí e de empresas de turismo de pesca esportiva, pelo uso de áreas do Complexo Ambiental Sacaí para o turismo. De acordo com os dísticos é possível evidenciar o esforço coletivo para a construção desse capital material comunitário.

“[...] nós temos uma casa de farinha lá embaixo da prefeitura, nós que fizemos lá, teve gente que não queria a casa de farinha, porque teve um tempo que os turistas entraram aqui atrás aí deixaram um dinheiro lá na prefeitura. Aí a gente resolveu fazer essa casa de farinha da gente aí" (J.C.A., 50 anos, Complexo Ambiental Sacaí).

"[...] nós temos a nossa casa de farinha ali, é lá na última casa. [...] do turismo, porque pescaram aqui por uma semana, aí nós não deixamos mais que eles pescassem, aí o rapaz obrigou ele a pagar a semana de pesca. [...] ele nos pagou três mil e quinhentos reais pela semana seguida de pesca. [...] um bocado quis o dinheiro e outros não quiseram. Aí quem quis o dinheiro, eu dei o dinheiro, recebi o dinheiro, e os que não quiseram se juntaram e fizeram uma casa de farinha. [...] para todo mundo" (A.B.S., 65 anos, Complexo Ambiental Sacaí).

A partir dos resultados do cruzamento entre as variáveis: (A) faz uso de alguma casa de farinha $x$ (B) faz uso da casa de farinha comunitária x (C) possui 
casa de farinha própria (Figura 5) é possível evidenciar a relevância assumida por esse capital material. Das 34 famílias não possuidoras de casa de farinha própria, 21 utilizam a estrutura comunitária. A casa de farinha coletiva aparece portanto como estrutura virtual de capitalização material da família comunitária.

Outro aspecto que apresenta evidência de compartilhamento é o mutirão para aceleração da colheita da roça em períodos em que a cheia ameaça tanto a produção quanto o beneficiamento da mandioca (Manihot esculenta Crantz). Os dísticos dos sujeitos apontam para processos coletivos de trabalho, desde a colheita até o descasque. Segundo os dísticos, é possível notar, em períodos críticos de colheita, perto de alagar as roças, o fato de esse tipo de trabalho ter aumento e tornar-se comum com o intuito de caracterizar relações de trabalho de ajuda mútua.

"[...] a colheita também não é muito difícil, você vai buscar uma mandioca ali, chego aqui, derramo aqui e não preciso convidar ninguém não, chega um bocado de mulher e tudo ajuda aí, dá uma força aí e não é pago não, as vezes a gente dá uma gratificação quando quer, às vezes a pessoa quando tá precisando, mas geralmente é só mesmo pra ajudar que eles vêm" (E.C.A., 58 anos, Complexo Ambiental Sacaí).

“[...] está lá a casa de farinha, na época em que a água está mais ou menos que a gente vê que vai alagar, aí o trabalho deles é só trazer para casa de farinha e todo mundo ajuda. [...] todo mundo vai ajudar ele ali, desde a torragem, aí rápido eles fazem. [...] as mulheres, e é muito rápido" (J.C.A., 50 anos, Complexo Ambiental Sacaí).

Nesse sentido, as redes de reciprocidade e o trabalho coletivo empreendidos no âmbito da família extensa comunitária dão ao Complexo Ambiental Sacaí os traços finais para garantir a recursividade no sistema familiar.

\section{Conclusões}

De maneira sumária, os dados apresentados permitem perceber a organização autopoiética familiar no Complexo Ambiental Sacaí apresentada primeiramente a partir da família nuclear. O reconhecimento dessa estrutura mais basal dá a condição necessária para transitar dentre as possíveis interações formadoras de outras estruturas familiares. Para isso, a capitalização material da casa e de elementos relacionados ao trabalho exercido no ambiente dá a entender a organização autopoiética familiar nuclear (re)construindo-se no sistema agrícola como agroecossistema familiar nuclear.

A família extensa troncal aparece como estratégia a partir das relações de parentesco, da aquisição do capital material de maior custo, extrapolando os limites da família nuclear. Nessa lógica comportam em si a (re) construção no sistema agrícola da família troncal como agroecossistema familiar troncal.

Finalmente, todos os moradores do Complexo Ambiental Sacaí compõem, juntos, a terceira tipologia de organização autopoiética familiar, a família extensa comunitária. As relações parentais consanguíneas nesse tipo de família não são necessárias, pois as redes de reciprocidade parecem ter sido propositalmente estruturadas como forma de suprir as diversas debilidades emergentes nesse sistema ambiental. As interações responsáveis por estruturar essa tipologia familiar são as mesmas responsáveis por (re)construir o sistema agrícola familiar comunitário em agroecossistema familiar comunitário.

Mesmo com a necessidade da distinção descritiva entre as três tipologias de organização autopoiética familiar, as quais remetem dialogicamente à ordem e à desordem no Complexo Ambiental Sacaí, o mesmo conserva em si a multiplicidade ainda como unidade, unitas multiplex (MORIN, 2002). Nesse sentido, fica evidente que, mesmo sendo todas, ela também é somente uma, (re)construindo-se recursivamente como agroecossistema familiar no Complexo Ambiental Sacaí.

\section{Referências}

ANDERSON, J. S. N. e SCHNEIDER, S. Brazilian Demographic transition and the strategic role of youth. Espace populations societés, v. 2-3, 2015.

ARANTES, E. C. Regularização fundiária e direito de propriedade na Amazônia legal: um estudo de caso do estado de Roraima (1998-2008). Tese (Doutorado) Porto Alegre, s.n., p. 316, 2009. 
BAREL, Y. The idea of reproduction. Futures, v. 1, n. 1, 1974.

BRASIL. Lein. 11.326, de 24 de julho de 2006. Dispõe sobre as diretrizes para a formulação da Política Nacional da Agricultura Familiar e Empreendimentos Familiares Rurais. Brasília: Presidência da República, 2006.

. Lei complementar no. 124, de 3 de janeiro de 2007. Institui, na forma do art. 43 da Constituição Federal, a Superintendência do Desenvolvimento da Amazônia. Brasília: Presidência da República, 2007. Disponível em: <http://www.planalto.gov.br/ccivil_03/LEIS/LCP/ Lcp124.htm>.

CANIÇO, H. et al. Novos tipos de família: plano de cuidados. Coimbra: Imprensa da Universidade de Coimbra, 2010.

DA SILVA, M. R. S. e LUNARDI, V. L. A concepção de família como unidade complexa. Família, Saúde e Desenvolvimento, v. 8, n. 1, p. 64-72, jan./abr. 2006.

DARNHOFER, I. et al. The resilience of farms: towards a relational approach. Journal o rural studies, v. 1, p. 111$122,2016$.

DELBOS, G. e JORION, P. La transmission des savoirs. Paris: Maison des Sciences de l'homme, 1984.

FACO, V. M. G. e MELCHIORI, L. E. Conceito de família: adolescentes de zona rural e urbana. In: VALLE, T. G. M. Aprendizagem e desenvolvimento humano: avaliações e intervenções. São Paulo: Cultura Acadêmica, 2009, p. 222.

FEMACT. Plano de estruturação do sistema de gerenciamento de recursos hídricos do estado de Roraima, Vol. II. Boa Vista: Simões Engenharia, 2007a.

Plano de estruturação do sistema de gerenciamento de recursos hídricos do estado de Roraima, Vol. III. Boa Vista: Simões Engenharia, 2007b.

GLIESSMANN, S. R. Agroecologia: processos ecológicos em agricultura sustentável. Porto Alegre: EDUFRGS, 2005.

GONZÁLEZ, A. B. Sucesión unipersonal y familia troncal en la "Catalunya Vella" (con algunas reflexiones conparativas). Revista de Antropología Social, v. 0, p. 179204, 1991.

GORZ, A. O imaterial: conhecimento, valor e capital. Trad. Celso Azzan Júnior; André Gorz. São Paulo: Annablume, 2005.

IBGE. Barcelos. Folha topográfica, Escala 1:250.000. [Online] 1983. Disponível em: <http://biblioteca.ibge. gov.br/index.php/biblioteca-catalogo?view=detalhes \&id=6900 > . Acesso em: 25 mar. 2016.
LEFEBVRE, H. Lógica formal, lógica dialética. Madrid: España Editores, 1983.

LEME, A. e BEGOSSI, A. Uso de recursos por ribeirinhos no Médio rio Negro. In: BEGOSSI, A. Ecologia de pescadores da Mata Altântica e da Amazônia. São Paulo: Hucitec, 2004, p. 89-148.

LIMA, V. Em RR, títulos expedidos de maneira ilegal pelo Iteraima são cancelados, 12 set. 2013. Disponível em: <http://g1.globo.com/rr/roraima/noticia/2013/09/ em-rr-titulos-expedidos-de-maneira-ilegal-peloiteraima-sao-cancelados.html>. Acesso em: 22 nov. 2015.

MARIOTTI, H. Preácio: outro olhar, outra visão. In: MATURANA, H. R. e VARELA, F. J. A árvore do conhecimento: as bases biológicas da compreensão humana. São Paulo: Palas Athenas, 2001.

MATURANA, H. R. e VARELA, F. J. A árvore do conhecimento: as bases biológicas da compreensão humana. São Paulo: Palas Athenas, 2011.

MORIN, E. O método II: a vida da vida. Trad. LOBO, M. Porto Alegre: Sulina, 2002.

. Ciência com consciência. Rio de Janeiro: Bertrand Brasil, 2008.

NODA, S. N. Na terra como na água: organização e conservação de recursos naturais terrestres e aquáticos em uma comunidade da Amazônia. Cuiabá, MT: PPGCB-IB-UFMT, 2000.

Agricultura familiar na Amazônia das águas. Manaus: EDUFAM, 2007.

., NODA, H. e MARTINS, A. L. M. A agricultura familiar na várzea amazônica: espaço e conservação da diversidade cultural e ambiental. In: SCHERER, E. e OLIVEIRA, J. A. Amazônia: políticas públicas e diversidade cultural. Rio de Janeiro: Garamond, 2006.

PERONDI, M. A. e SCHNEIDER, S. Bases teóricas da abordagem de diversificação dos meios de vida. REDES - Revista desenvolvimento regional, v. 17, n. 2, mai/ago. 2012, p. 117-135.

RADOMSKY, G. e SCHNEIDER, S. Nas teias da economia: o papel das redes sociais e da reciprocidade nos processos locais de desenvolvimento. Sociedade $e$ Estado, v. 22, n. 2, maio/ago. 2007.

RORAIMA. Diário oficial, 26 de janeiro de 2009. Decreto n. 9699 de 23 de janeiro. Boa Vista, Roraima, Brasil: DOE-RR, 23 de janeiro de 2009, p. 1-6. Dispõe sobre o decreto de criação do ITERAIMA. 
SABOURIN, E. P. Gestão territorial e economia social e solidária: uma análise pela reciprocidade. Guaju, v. 1, n. 1, jan./jun. 2015, p. 3-26.

SÁNCHEZ, C. V. La familia: cambios, conceptos y nuevos modelos. La Revue du REDIF, v. 1, p. 15-22, 2008.

TUAN, Y. Topofilia: um estudo da percepção, atitudes e valores do meio ambiente. Trad. L. Oliveira. Londrina: Eduel, 2012.
WALSH, F. The New Normal: diversity and complexity in 21st-century families. Normal Family Processes: growing diversity and complexity. New York: Guilford Press., 2016, p. 575.

YIN, R. K. Estudo de caso: planejamento e métodos. In: DAMACENA, C. (Ed.). Trad. A. Thorell. Porto Alegre: Bookman, 2010.

Todo o conteúdo deste periódico, exceto onde estiver identificado, está licenciado sob uma Licença Creative Commons (cc by 4.0). 
